\title{
Jaringan Advokasi Transnasional (GAATW) dalam Penyelesaian Isu Migrasi Pekerja Perempuan dan Perdagangan Manusia di Asia Tenggara
}

\author{
Monica Vira Ajeng Kristanti \\ Universitas Indonesia
}

\begin{abstract}
Abstrak
Asia Tenggara merupakan salah satu kawasan yang memiliki tingkat migrasi pekerja cukup tinggi, baik sebagai negara penyumbang maupun penerima. Namun, hal ini tidak disetarai dengan regulasi dan hukum yang tegas. Pelanggaran terhadap hak-hak pekerja migran banyak ditemukan di beberapa negara. Jaringan Advokasi Transnasional (TAN) hadir untuk memberikan rekomendasi dan advokasi kepada pekerja migran secara lintas negara. Dalam artikel ini, jaringan advokasi transnasional yang akan dikaji lebih lanjut adalah Global Alliance Against Trafficking in Women (GAATW) yang telah aktif melakukan advokasi dan memberikan rekomendasi kebijakan ke lima negara di Asia Tenggara yaitu Indonesia, Singapura, Kamboja, Filipina, dan Thailand. Metode penelitian yang digunakan dalam penelitian ini adalah metode kualitatif dengan menggunakan data sekunder. Dalam penelitian ini, kita dapat melihat bagaimana GAATW bekerjasama dengan beberapa serikat pekerja migran di negara-negara tersebut baik dengan melakukan penelitian, advokasi korban, maupun dengan menerbitkan hasil publikasi yang ditujukan kepada publik dan pemerintah.
\end{abstract}

Kata kunci: Jaringan Advokasi Transnasional; Pekerja Imigran; Perempuan

Southeast Asia is one of the regions that has a fairly high rate of labor migration, both as a contributor and a recipient country. However, this is not equated with strict regulations and laws. Violations of the rights of migrant workers are common in several countries. The Transnational Advocacy Network (TAN) is here to provide recommendations and advocacy to migrant workers across countries. In this article, the transnational advocacy network that will be studied further is the Global Alliance Against Trafficking in Women (GAATW) which has been actively advocating and providing policy recommendations to five countries in Southeast Asia, namely Indonesia, Singapore, Cambodia, the Philippines, and Thailand. The research method used in this study is a qualitative method using secondary data. In this study, we can see how GAATW cooperates with several migrant worker unions in these countries, either by conducting research, advocating for victims, or by publishing publications aimed at the public and the government.

Keywords: Migrant Workers; Transnational Advocacy Network; Women 


\section{Pendahuluan}

Asia Tenggara merupakan salah satu kawasan dengan migrasi pekerja yang cukup tinggi, terutama sejak dimulainya Masyarakat Ekonomi ASEAN (MEA) dan beberapa sektor formal yang ditambahkan sebagai salah suatu bentuk kompetisi perekonomian baru dalam ASEAN. Kerjasama Association of Southeast Asian Nations (ASEAN) dalam ekonomi merupakan salah satu upaya untuk menyelaraskan perkembangan ekonomi masing-masing negara ASEAN. Pasalnya, masing-masing negara anggota memiliki kemampuan ekonomi yang berbeda dan cenderung 'timpang'. Seperti adanya perbedaan signifikan dari segi penghasilan per kapita antara Laos dengan 119 USD, dan Singapura dengan 3547 USD. Melihat hal ini, MEA memberikan kesempatan bagi maisng-masing negara anggota untuk dapat meningkatkan kualitas SDA-nya agar dapat bersaing secara regional (German Asia-Pasific Bussines Association 2020).

Pekerja migran memberikan pengaruh yang signifikan terhadap pertumbuhan ekonomi negara asalnya masing-masing. Meskipun pekerja migran memberikan pengaruh positif terhadap pertumbuhan ekonomi negara, para pekerja seringkali tidak mendapatkan perlindungan yang sesuai baik secara birokrasi, maupun diskriminasi yang seringkali menimpa pekerja perempuan. Selain itu, pekerja migran juga memiliki resiko untuk menjadi korban perdagangan manusia. International Labour Organization (ILO) melihat bahwa hal-hal ini seringkali tidak menjadi perhatian pemerintah. Pekerja migran yang bekerja untuk sektor domestik atau low-skilled labor yang biasanya dilakukan oleh perempuan beresiko tereksploitasi dan menjadi korban kekerasan (ILO 2020). Meskipun lapangan pekerjaan yang dapat dilakukan oleh para pekerja migran cukup luas, pekerjaan-pekerjaan tesebut cenderung didominasi oleh laki-laki. Pekerja perempuan cenderung bekerja dibidang pelayanan. Adapun masalah lain yang juga menjadi isu dalam pekerja migran adalah banyaknya jumlah pekerja migran yang tidak terdokumentasi sehingga para pekerja tidak mendapatkan jaminan-jaminan yang seharusnya didapatkan (ILO 2020).

Berdasarkan artikel yang ditulis oleh PBB mengenai pekerja migran perempuan di ASEAN, yang berjudul "Women Migrant Workers, in ASEAN Economic Community" terdapat beberapa poin penting terkait mengapa perempuan menjadi salah satu pihak yang rawan mengalami ketidakadilan dalam kerjasama ekonomi antar negara-negara ASEAN tersebut. Pertama, yakni terhitung sejak tahun 2015, pekerja migran perempuan berjumlah kurang lebih $48.5 \%$ dari total keseluruhan pekerja migran intra-ASEAN. Kedua, adanya pekerja migran perempuan merupakan bagian penting dari angkatan kerja di negara tujuan ASEAN 
meskipun data menunjukkan bahwa penghasilan pekerja migran perempuan lebih rendah 2-4\% dari laki-laki. Ketiga, yakni rumah tangga, agrikultur, dan manufaktur adalah sektor-sektor utama yang didominasi perempuan. Keempat, yakni pekerja migran perempuan rata-rata masih berusia muda dan masuk dalam bagian low-skilled labor, kelima penghasilan yang diterima oleh para pekerja migran perempuan lebih rendah dari laki-laki atau gender pay gap yang signifikan, terakhir, pekerja migran perempuan berkontribusi signifikan terhadap perekenomian negara tujuan (ASEAN Secretariat Jakarta 2017).

Global Alliance Against Trafficking in Women (GAATW) merupakan salah satu bentuk jaringan transnasional yang berupaya untuk menyelesaikan isu migrasi dan perdagangan perempuan di Asia. GAATW sendiri melihat adanya beberapa urgensi mengenai migrasi pekerja perempuan di Asia yaitu adanya pekerja migran perempuan yang 'terjebak' di sektor kerja yang itu-itu saja. Kebanyakan sektor kerja yang terbuka bagi perempuan adalah sektor-sektor low-skill. Para pekerja perempuan juga mendapatkan bayaran yang lebih rendah dan rawan eksploitasi dan kekerasan. Hal ini yang menyebabkan beberapa organisasi masyarakat di berbagai negara bergabung dalam GAATW untuk menyelesaikan masalah-masalah tersebut (GAATW 2020). GAATW memiliki lima anggota yang merupakan anggota ASEAN yaitu Filipina, Indonesia, Thailand, Kamboja, dan Singapura. GAATW telah menjadi representasi yang baik di ASEAN, terutama karena GAATW telah beberapa kali berpartisipasi dalam forum-forum ASEAN. GAATW sendiri pernah berpartisipasi dalam ASEAN People's Forum atau APF sebagai representatif dari kelompok Customer Service Officer (CSO) dan individu (GAATW 2020).

Berdasarkan beberapa faktor tersebut kemudian menjadi suatu alasan penulis untuk menjawab permasalahan dari isu migrasi pekerja perempuan di Asia Tenggara yang dilihat dari segi peran Transnational Advocacy Network (TAN). Adapun metode yang digunakan dalam penelitian ini adalah metode kualitatif dengan melakukan pengambilan data sekunder. Artikel jurnal ini dibuat untuk memberikan fakta dan rekomendasi terkait hal-hal yang perlu diperhatikan oleh ASEAN untuk dapat meningkatkan perekonomian dan kebijakan terkait pekerja migran di Asia Tenggara.

\section{Transnational Advocacy Network}

Di era globalisasi, peran dari aktor-aktor non negara (NGO) sangat penting dalam proses pengambilan keputusan. Aktor-aktor tersebut hadir dalam ranah lokal hingga global. Dalam ranah lokal, NGO biasanya dapat 
membentuk jaringan-jaringan dengan NGO lain yang memiliki konsentrasi dalam isu yang sama di ranah global. Adapun, aktor-aktor dalam TAN meliputi lembaga penelitian dan advokasi, gerakan sosial, agamawan dan serikat-serikat, organisasi regional dan internasional, serta parlemen. Isu yang diangkat oleh TAN pun beragam seperti Hak Asasi Manusia (HAM), isu perempuan, tatanan, lingkungan, serta pembangunan (Keck dan Sikkink 1998).

Dalam TAN yang dijabarkan oleh Keck dan Sikkink, keduanya memberikan penjelasan mengenai Boomerang Pattern. Boomerang Pattern merupakan upaya yang dilakukan oleh NGO untuk mendapatkan perhatian internasional, yang kemudian dapat membantu untuk memenuhi apa yang menjadi tujuan utamanya. Hal ini dilakukan untuk memperkuat jaringan NGO saat mengalami kebuntuan. Adanya penguatan jaringan yang dilakukan oleh NGO lokal bersama dengan NGO internasional diharapkan mampu memberikan tekanan bagi pemerintah untuk melakukan apa yang diharapkan oleh NGO lokal tersebut. Adapun, gambaran umum mengenai Boomerang Pattern yang dijelaskan oleh Keck dan Sikkink yaitu jika sebuah NGO sudah tidak dapat lagi melakukan sesuatu untuk menyelesaikan isu domestik di negaranya, NGO tersebut dapat membentuk jaringan dengan NGO di luar negeri. Jaringan tersebut digunakan untuk melakukan pertukaran informasi, bantuan advokasi, hingga bantuan finansial (Keck dan Sikkink 1998).

\section{GAATW di Filipina}

Filipina merupakan salah satu negara yang memiliki beberapa kelompok buruh dan anti perdagangan manusia yang tergabung dalam jaringan GAATW. Lembaga yang tergabung dalam GAATW ini adalah Buhay Foundation for Women and Girl Child. GAATW sendiri melakukan berbagai advokasi di Filipina, salah satunya adalah melakukan advokasi terkait perlindungan peserta program Au Pair dari Filipina di Eropa. Isu ini diangkat karena banyak kasus mengenai eksploitasi pekerja Au Pair dan pola-pola migrasi yang menyulitkan bagi calon pekerja. Pada tahun 2012, pemerintah Filipina menghentikan program emigrasi warga negara Filipina melalui program Au Pair. Hal ini dilakukan untuk mengurangi perginya para pekerja yang tidak terdokumentasi, di satu sisi, banyak lembaga non-pemerintah di Eropa yang sedang melakukan advokasi dan protes pemerintah untuk merevisi skema program tersebut (GAATW 2013).

Advokasi ini dilakukan melihat meningkatnya 'tren' kebutuhan pekerja migran di Eropa dalam beberapa sektor pekerjaan, namun tidak disertai 
dengan berbagai fasilitas yang menjamin keamanan dan kenyamanan bagi pendatang, khususnya pekerja migran perempuan. Program ini seringkali diartikan sebagai "pertukaran budaya", padahal praktiknya berbeda sekali dengan yang ada di lapangan. Kondisi ini diperburuk karena seringkali, migran Au Pair yang berasal dari Filipina merupakan tulang punggung keluarga masing-masing (GAATW 2013).

Upaya jaringan transnasional ini dilakukan oleh lembaga non-pemerintah di Filipina dan lembaga non-pemerintah di Denmark. Lembaga-lembaga Filipina memberikan data berupa dokumen wawancara serta memberikan data-data yang dapat membantu pembuatan working paper berjudul " $\mathrm{Au}$ Pair Challenges to Safe Migration and Decent Work" yang dipublikasikan oleh GAATW pada tahun 2013. Adapun publikasi ini dilakukan sebagai sarana advokasi para pekerja $A u$ Pair dengan pemerintah Filipina dan beberapa negara Eropa yang menjadi tujuan destinasi bagi pekerja Filipina (GAATW 2013). Selain itu, lembaga non pemerintah yang turut serta membantu dalam melakukan pemberian data dan analisa lebih lanjut setelah working paper dipublikasikan adalah Center for Migrant Advocacy Philippines (CMA) (CMA 2014).

Kerjasama yang dilakukan oleh CMA dan GAATW terbatas pada bantuan advokasi tidak langsung semata. Publikasi yang diterbitkan oleh GAATW bertujuan untuk mendesak pemerintah Filipina untuk memperbaiki kebijakan terkait program Au Pair. Baik CMA dan GAATW, keduanya sama-sama mengeluarkan publikasi terkait program $A u$ Pair yang ditujukan pada pemerintah. Datanya pun terlihat mirip, yang membedakan adalah bagaimana GAATW juga turut melibatkan lembaga non-pemerintahan di Eropa seperti FOA Union dan menyasar pada dua pemerintahan baik pemerintah Filipina dan pemerintah negaranegara tujuan di Eropa itu sendiri. Beberapa poin yang menjadi perhatian bagi kedua pihak adalah usia minimal dan maksimal penerima program $A u$ Pair, keluarga yang ditinggalkan oleh para pemegang visa Au Pair, adanya peserta yang tidak terdokumentasi, serta kurangnya bimbingan pemerintah terkait program ini sebelum peserta pergi ke negara tujuan. Selain itu, banyak pekerja perempuan yang rawan menjadi korban kekerasan dan perdagangan manusia (CMA 2014).

Pada tahun 2020 ini, pemerintah Filipina telah memberikan aturan tambahan mengenai penyelenggaraan program $A u$ Pair dengan menambahkan beberapa poin dan persyaratan bagi pendaftar. Namun, hal ini tidak dapat dipastikan apakah penambahan poin-poin ini disebabkan oleh advokasi yang dilakukan oleh GAATW. 


\section{GAATW di Indonesia}

Indonesia merupakan salah satu negara yang memiliki beberapa kelompok buruh dan anti perdagangan manusia yang tergabung dalam jaringan GAATW. Adapun, lembaga-lembaga non pemerintahan yang tergabung dalam GAATW di Indonesia adalah Pendidikan Khusus Profesi Advokat (PKPA), Solidaritas Perempuan (SP), Yayasan Annisa Swasti (YASANTI), Legal Resource Center untuk Keadilan Jender dan HAM (LRC-KJHAM), dan Institut Perempuan (IP).

Kerjasama yang terjadi antara lembaga-lembaga tersebut dan GAATW tidak jauh berbeda dengan kerjasama yang dilakukan oleh GAATW di Filipina. Salah satu contoh lembaga yang tergabung dalam GAATW yaitu SP, telah melakukan koordinasi seperti pemberian informasi dan data, pembentukan strategi kebijakan, melakukan kampanye, serta melakukan advokasi (Yazid 2020). Partisipasi lembaga-lembaga di Indonesia dalam GAATW pun terbilang hanya sebatas pada advokasi dan dukungan kampanye semata. Salah satu isu dimana GAATW terjun langsung dalam penyelesaian inti masalah adalah projek pendidikan terhadap pekerja migran perempuan di Curut, Jawa Tengah dengan kerjasamanya bersama Forty Percent Againts Right (FPAR) melalui program Safe and Fair pada tahun 2018-2019.

Proyek ini dilakukan karena adanya peningkatan terhadap jumlah pekerja migran, khususnya perempuan. Perempuan sendiri rentan mengalami ketidakadilan dalam isu ini. Selain itu, banyak perempuan yang bekerja pada sektor-sektor low-skilled. Adanya pendidikan yang diberikan dalam proyek ini diharapkan mampu meningkatkan keterampilan perempuan pekerja migran. Guna memudahkan projek ini terutama dalam kesulitan bahasa dan pemahaman, projek ini dibantu oleh LRC-KJHAM yang memang telah menjadi mitra dari GAATW (LRCKJHAM 2020). Proyek ini dilakukan dengan mengumpulkan 29 partisipan yang tinggal di Curut, Jawa Tengah yang masing-masing berlatar belakang pendidikan lulusan SD, SMP, dan SMA. Sembilan dari partisipan pernah melakukan migrasi ke luar negeri saat masih di bawah umur. Arab Saudi merupakan salah satu destinasi yang paling banyak menjadi tujuan migrasi. Selain Arab Saudi, terdapat Taiwan, Singapura, Hongkong, dan Malaysia sebagai negara tujuan (LRCKJHAM 2020).

Proyek ini dilakukan dengan berbagai langkah, salah satunya adalah melalui Focus Group Discussion (FGD). FGD dilakukan dengan membahas beberapa topik penting sebagai pembelajaran seperti seks dan gender, proses rekrutmen dan kondisi tempat penampungan, proses keberangkatan, kondisi lingkungan kerja di negara tujuan, proses migrasi 
yang aman bagi perempuan, kondisi lingkungan kerja bagi perempuan di negara tujuan, membuat rekomendasi hasil diskusi, serta memberikan perkembangan terkait projek dan penelitian dari FPAR kepada partisipan. Kegiatan lain yang dilakukan dalam projek ini adalah wawancara dan menulis (LRCKJHAM 2020). Hasilnya banyak partisipan yang menyatakan bahwa latar belakang pendidikan dan kurangnya lapangan pekerjaan di dalam negeri adalah salah satu faktor yang menyebabkan para partisipan memilih bekerja di luar negeri di usia yang masih muda. Faktor lainnya adanya kekerasan dalam rumah tangga yang menyebabkan beberapa partisipan memilih meninggalkan rumah mereka. Perubahan iklim juga menjadi salah satu faktor bagi partisipan untuk meninggalkan rumah karena mereka sudah tidak dapat bercocok tanam lagi (LRCKJHAM 2020).

Terdapat banyak pelanggaran hak saat bekerja yang disampaikan oleh partisipan seperti adanya kekerasan seksual dan pemaksaan, pelarangan penggunaan atribut keagamaan, pemotongan gaji, hingga tidak diberikan waktu libur. Saat kembali ke Indonesia pun, beberapa partisipan mengalami kesulitan untuk mendapatkan kembali dokumen-dokumen penting seperti Kartu Tanda Penduduk (KTP) dan ijasah yang biasanya ditahan oleh pihak agensi. Berdasarkan isu-isu ini, GAATW, LRC-KJHAM, dan FPAR memberikan beberapa rekomendasi yang dapat digunakan sebagai advokasi kepada pemerintah seperti memperkuat hukum yang ada terkait isu migran terutama terhadap perempuan, serta menindak tegas agensi-agensi yang marak melakukan penipuan demi keuntungan. Pemerintah juga perlu memberikan perlindungan hukum terhadap korban kekerasan dan korban penipuan. Terakhir, pemerintah perlu menyediakan lembaga resmi yang dapat memberikan pelatihan bagi calon pekerja migran, agar para pekerja migran dapat memahami hak dan kewajiban, serta kondisi lingkungan kerja di daerah tujuan (LRCKJHAM 2020).

\section{GAATW di Thailand}

Thailand merupakan tempat dimana GAATW pertama kali berdiri pada tahun 1994, sekaligus sebagai pusat GAATW beroperasi. Adapun, beberapa organisasi kemanusiaan yang tergabung dalam GAATW di Thailand adalah Gabfai Community, Foundation For Women, Association of Human Rights and Women's Rights in Development (AWARD) (GAATW 2020). Salah satu isu yang menjadi kekhawatiran bersama di Thailand adalah perdagangan manusia dan pemaksaan prostitusi di beberapa industri seks yang ada di Thailand. Selain menjadi salah satu penyumbang pekerja migran ke luar negeri, Thailand juga cukup banyak menerima pekerja migran yang masuk ke dalam negeri 
khususnya di bidang pariwisata. Kebanyakan pekerja migran yang datang ke Thailand berasal dari negara-negara seperti Burma, Kamboja, dan Laos. Dalam hal ini, salah satu hal yang dilakukan oleh GAATW adalah dengan membuat publikasi terkait penanganan dan penyelesaian yang dilakukan oleh lembaga-lembaga terkait di Thailand serta berupaya memberikan rekomendasi. GAATW juga memberikan beberapa projek dengan negara-negara yang menjadi salah satu penyumbang terbesar pekerja migran ke Thailand (GAATW 2007).

Salah satu isu yang menjadi perhatian dalam masalah pekerja migran di Thailand adalah human trafficking. Isu perdagangan manusia, khususnya perempuan di Thailand merupakan masalah yang serius. Pasalnya kebanyakan korban dipaksa bekerja di ranah prostitusi. Kegiatan ilegal ini juga meningkatkan potensi menularnya berbagai penyakit menular seksual. Dalam data yang ditemukan dan disampaikan oleh Thai Labour Committee, advokasi seringkali sulit dilakukan. Maka dari itu komunitas pekerja sangat dianjurkan untuk bersatu dalam penyelesaian isu ini, agar nantinya banyak kejadian serupa tidak terulang kembali. Para pekerja seks komersial juga turut bersatu dan memiliki lembaganya sendiri, untuk mencegah adanya kegiatan penggelapan dan perdagangan manusia (GAATW 2007).

Pemerintah Thailand menyadari banyaknya gelombang pekerja migran yang keluar dan masuk di negaranya dan telah menyediakan agensi dibawah pemerintah untuk mengurus hal-hal terkait dokumen dan keberangkatan, serta penerimaan. Namun, hal ini dianggap tidak efektif. Salah satu hal yang menjadi penyebab mengapa isu ini sangat sulit ditangani adalah rumitnya kebijakan dan aturan terkait pekerja migran di Thailand. Pemerintah Thailand mengharuskan pekerja migran untuk membayar sejumlah uang yang tidak murah, serta birokrasi yang rumit dan panjang. Oleh karenanya, banyak dari pekerja migran memilih untuk menggunakan agensi swasta. Banyak calon pekerja migran yang juga malah menjadi korban penipuan dan korban perdagangan. Hal ini pun telah disampaikan oleh beberapa organisasi buruh migran sejak tahun 2007, namun belum mendapatkan hasil yang diharapkan. Beberapa aturan dan hukum terkait perdagangan manusia dan pemaksaan prostitusi pun sebenarnya telah dimiliki. Namun hukum tersebut seakan tidak berjalan dengan benar sebagaimana mestinya (GAATW 2007).

GAATW juga kembali bekerjasama dengan FPAR dalam projek Safe and Fair di Thailand, untuk melakukan advokasi dengan pekerja migran dari Myanmar. Adapun program ini dilakukan karena Myanmar merupakan salah satu penyumbang terbesar pekerja migran yaitu sekitar $82 \%$ di 
Thailand, terutama pada sektor industri garmen. Proyek ini dilakukan untuk mendalami lebih langsung mengenai kondisi lingkungan kerja dan tempat tinggal dari para pekerja migran. Hasil dari proyek ini merupakan rekomendasi yang disampaikan baik kepada pemerintah Thailand maupun Myanmar. Hasilnya banyak ditemukan beberapa pelanggaran hak-hak pekerja. Hal ini didasari oleh ketidaktahuan para pekerja terkait hak-hak yang seharusnya mereka dapatkan. Para pekerja migran tidak mendapatkan jaminan kesehatan, penahanan dokumen dan harus membayar sejumlah uang untuk mendapatkannya kembali, serta tidak dapat melakukan aksi protes pada hari buruh karena ancaman pemecatan. Rekomendasi yang dituliskan oleh GAATW meliputi, perubahan terkait beberapa aturan dalam proses rekrutmen, pemberian upah yang setara dengan jam kerja, serta pengadaan pelatihan pekerja (MAP foundation 2020).

\section{GAATW di Singapura}

GAATW bekerjasama dengan Transient Workers Count Too (TWC2). TWC2 pun terbilang cukup progresif dalam hal advokasi dan publikasi. Sama seperti Thailand, Singapura merupakan salah satu negara yang banyak menerima pekerja migran dari luar negeri, salah satunya Indonesia. Maka dari itu, TWC2 hadir untuk memberikan advokasi terhadap pekerja-pekerja migran yang membutuhkan. TWC2 melihat adanya ketidakadilan yang dirasakan oleh para pekerja migran di Singapura, terutama bagi mereka yang bekerja di sektor-sektor low-skill, karena kurangnya regulasi yang memberikan perlindungan terhadap mereka (TWC2 2020).

Salah satu publikasi yang dilakukan oleh GAATW dan TWC2 adalah dengan melakukan kajian ulang terhadap implementasi Convention on Elimination of all forms of Discrimation Against Women (CEDAW) di Singapura. Kedua lembaga tersebut melihat adanya ketidakadilan yang terjadi terhadap pekerja migran seperti rasisme, kurangnya upah yang dibayarkan, dan lain sebagainya. Selain itu, isu lain yang diangkat adalah bagaimana beberapa pekerja sulit mendapatkan fasilitasfasilitas kesehatan meskipun izin kerja telah dimiliki. Padahal, untuk mendapatkan izin kerja juga dibutuhkan syarat-syarat yang rumit (TWC2 2020). Beberapa poin dalam CEDAW seakan tidak dilaksanakan berurutan dengan kebijakan yang dilakukan oleh pemerintah Singapura. Kerjasama antara GAATW dan TWC2 ini dilakukan untuk memberikan rekomendasi kepada pemerintah terkait kebijakan yang sesuai untuk para pekerja migran.

Dalam beberapa kasus, ditemukan beberapa pekerja migran di sektor 
domestik kehilangan beberapa dokumentasinya karena majikan melakukan penahanan paspor dan KTP agar pekerja domestik tidak 'kabur'. Dalam kasus yang penulis temukan di Kedutaan Besar Republik Indonesia (KBRI) Singapura pada tahun 2018, banyak pekerja domestik yang harus tinggal di asrama yang disediakan oleh KBRI sebagai tempat tinggal. Hal ini dikarenakan beberapa dokumen dan urusan yang belum selesai dengan majikan sebelumnya. Mereka pun diharuskan untuk rutin melaporkan diri ke Ministry of Menpower atau MoM untuk tetap mendapatkan izin tinggal di Singapura sampai isu tersebut selesai (Kristanti 2018).

Adapun beberapa rekomendasi yang diberikan yaitu menghilangkan segala bentuk diskriminasi terhadap pekerja migran, meliputi pemberian akses yang mudah untuk mendapatkan akses kesehatan dan fasilitas umum lainnya bagi para pemegang izin kerja, menghilangkan larangan bagi pekerja perempuan untuk memiliki anak di Singapura, larangan untuk menikah bagi pekerja migran, akses bagi para pekerja migran yang sedang mengalami permasalahan dengan majikan untuk bekerja, proteksi hukum yang legal bagi para pekerja migran, serta menghilangkan sikap-sikap rasisme yang dilakukan oleh majikan terhadap pekerja. Rekomendasi juga diberikan kepada pemerintah untuk membuat kebijakan yang sesuai bersama dengan negara-negara ASEAN lainnya untuk melakukan perlindungan terhadap para pekerja migran di seluruh negara di Asia Tenggara serta memperkuat hubungan bilateral dengan negara-negara terkait untuk menyediakan akses yang mudah serta mencegah adanya pekerja migran ilegal (TWC2 2020).

\section{GAATW di Kamboja}

Kamboja merupakan salah satu negara dengan jumlah pekerja migran yang cukup tinggi. Adapun, beberapa lembaga yang secara resmi tergabung dalam GAATW di Kamboja adalah Cambodia Women's Crisis Center (CWCC), Cambodian Women's Development Agency (CWDA), dan Legal Support for Children and Women (LSCW) (GAATW 2020). Sama seperti kerjasama lainnya, GAATW dan Kamboja berfokus pada advokasi dan publikasi.

Salah satu projek yang dilakukan oleh GAATW merupakan proyek Safe and Fair yang dilakukan bersama dengan FPAR dan Cambodian Alliance of Trade Union (CATU). Publikasi tersebut berfokus pada industri garmen dan serikat pekerja yang ada di Kamboja. Dalam penelitian lapangan yang ditemukan, terdapat lebih dari 53\% pekerja migran Kamboja yang menggunakan jalur illegal untuk dapat bekerja di luar negeri. Hal ini tentu membahayakan keselamatan dari masing-masing 
pekerja, terutama perempuan (CATU Cambodia 2020). Perkembangan serikat pekerja di Kamboja dapat dibilang cukup progresif. Pada tahun 2019, terdapat lebih dari seratus organisasi serikat pekerja yang membantu untuk melakukan advokasi terhadap pekerja migran yang masuk ke Kamboja dan sebaliknya. Adanya serikat-serikat ini berhasil melakukan penekanan terhadap beberapa perusahaan tekstil atau garmen yang melakukan ketidakadilan bagi para pekerjanya dengan melakukan aksi protes besar-besaran (CATU Cambodia 2020).

Publikasi lainnya yang dilakukan oleh GAATW terkait isu pekerja migran Kamboja adalah dengan melakukan penelitian terhadap pekerja migran Kamboja di Thailand terutama di sektor industri garmen. Penelitian ini dilakukan dengan melakukan kerjasama dengan LSCW Kamboja. Hal ini dilakukan karena Thailand mendapatkan kecaman dari berbagai perserikatan buruh pekerja migran di Kamboja terkait beberapa hal termasuk jaminan kesehatan, izin kerja, hingga lokasi tempat tinggal dan lingkungan kerja (GAATW 2020). Adapun beberapa hal yang menjadi perhatian GAATW dan LSCW adalah kurangnya kesadaran para pekerja mengenai hak-hak yang seharusnya didapatkan dan perjanjianperjanjian yang tertulis dalam dokumentasi pekerja, ketidakmampuan pekerja untuk membedakan kewajiban dan eksploitasi, serta adanya ketakutan bahwa para pekerja tidak akan mendapat bantuan karena mereka datang dengan menggunakan agensi non pemerintah (GAATW 2020). Beberapa rekomendasi yang dilampirkan meliputi pengadaan agensi resmi untuk menyampaikan aduan, akses yang singkat dan birokrasi yang tepat untuk mendapatkan izin kerja, adanya fleksibilitas dalam memilih pekerjaan, serta adanya regulasi dan kontrak yang jelas antara pemberi kerja dan pekerja (GAATW 2020).

\section{Kesimpulan}

GAATW memberikan kesempatan bagi masing-masing serikat pekerja untuk melakukan penelitian dan mengakomodasi kepentingankepentingan para pekerja migran. Namun, GAATW sendiri terbatas pada pemberian rekomendasi dan advokasi. Dalam melakukan bantuan advokasi dan publikasi pada negara-negara yang menjadi penyumbang tenaga kerja migran, GAATW seringkali melakukan penelitian dan proyek langsung dengan bekerjasama dengan lembaga-lembaga lokal. Hal ini dilakukan untuk melihat perspektif dari para pekerja migran, agar pembuatan rekomendasi terkait isu ini dapat menyasar pada orang-orang yang langsung menjadi korban ketidakadilan. Salah satu hal yang menjadi perhatian adalah bagaimana GAATW juga mengakomodasi negara-negara 
penerima pekerja migran seperti Thailand dan Singapura. Hal ini dapat mempercepat proses akomodasi advokasi dan publikasi dan memberikan tekanan langsung kepada negara-negara yang melanggar hak-hak pekerja.

Adapun GAATW tidak banyak menyampaikan bagaimana Asia Tenggara atau ASEAN sebagai organisasi regional harus bertindak dalam menanggapi isu ini. GAATW hanya berfokus pada masing-masing negara, dan tetap menyampaikan bahwa ASEAN harus bertindak sebagai masyarakat ekonomi untuk turut melakukan perlindungan terhadap para pekerja migran di tiap-tiap rekomendasi dalam publikasinya. Hal ini juga dikarenakan kurangnya partisipasi lembaga non-pemerintahan di ASEAN, sehingga banyak informasi penting yang seakan tidak tersampaikan. GAATW juga diharapkan mampu memberikan advokasi lebih daripada publikasi dan penelitian semata guna mencapai tujuan awal terbentuknya GAATW itu sendiri. Adapun jaringan transnasional yang dilakukan oleh serikat pekerja di masing-masing negara yang tergabung dalam GAATW terbilang efektif dalam hal advokasi terhadap korban. Hal ini terbukti dari adanya beberapa program atau projek yang dilakukan untuk memberikan pengajaran dan pengawasan terhadap mantan pekerja migran di Indonesia. Dalam memberikan tekanan terhadap pemerintah, jaringan transnasional kurang memberikan tekanan. Seperti pada kasus di Kamboja, pemerintah seakan lebih takut pada ratusan jaringan kelompok tenaga kerja lokal yang melakukan demo besar-besaran. Namun, publikasi yang dilakukan oleh GAATW sangat membantu masyarakat internasional untuk dapat memberikan dukungan dan tekanan pada negara-negara yang melakukan pelanggaran hak pekerja.

Sebagai opini pribadi, jaringan transnasional sangat penting dalam mengakomodasi kepentingan tenaga kerja migran terutama dalam hal advokasi. Dalam kasus ini, jaringan transnasional juga membantu serikat pekerja migran untuk menyampaikan aspirasi melalui publikasi yang diterbitkan. Meskipun sasarannya tidak langsung tepat pada pemerintah, namun jaringan transnasional merupakan salah satu langkah yang cukup efektif untuk melakukan perubahan kebijakan agar aspirasi dari individu dapat dipertimbangkan. Adapun, jaringan transnasional mungkin akan sia-sia apabila tidak ada aksi yang seimbang dari pemerintah. Pemerintah juga perlu terbuka terhadap isu-isu yang menjadi perhatian dari jaringan transnasional. 


\section{Daftar Pustaka}

\section{Buku}

Keck, M. E., dan Sikkin, Kathryn, 1998. Activists beyond Borders: Advocacy Networks in International Politics. New York: Cornell University Press. 1-38

\section{Publikasi Daring}

ASEAN Secretariat Jakarta, 2017. Women Migrant Workers In The ASEAN Economic Community. Bangkok: UN Women. [Daring]. Tersedia dalam [https://asean.org/storage/2012/05/AEC-Women-migration-study.pdf] (Diakses [21 April 2020]).

CATU Cambodia, 2020. Feminised Migration and Deteriorating Conditions of Employment in The Garment Industry in Cambodia: Perspectives of Workers Organised by CATU. GAATW. [Daring]. Tersedia dalam [https://gaatw.org/publications/Safe and Fair FPAR/FPAR Report CATU.pdf] (Diakses [19 Juni 2020]).

CMA, 2014. Philippine Migration And Au Pair Programs in Europe. [Daring]. Tersedia dalam [https://centerformigrantadvocacy.files. wordpress.com/2014/04/cma-philippine-migration-and-au-pairprograms-in-europe-2014.pdf] (Diakses [17 Mei 2020]).

GAATW, 2007. Collateral Damage: The Impact of Anti-Trafficking Measures on Human Rights Around The World. [Daring]. Tersedia dalam [http://www.gaatw.org/Collateral\%20Damage Final/CollateralDamage THAILAND.pdf] (Diakses [19 Mei 2020]).

, 2013. Au Pair Challenges to Safe Migration and Decent Work. [Daring]. Tersedia dalam [https://www.gaatw.org/publications/ AuPair ChallengestoSafeMigrationandDecentWork.GAATW2013. pdf] (Diakses[ 17 Mei 2020]).

, 2020. Access Unknown, Access to Justice From The Perspectives

Of Cambodian Migrant Workers in Thailand. [Daring]. Tersedia dalam [http://www.gaatw.org/publications/GAATW Access\%20Unknown Thai-Cambodia\%20ResearchProject.2017.pdf] (Diakses [19 Juni 2020]).

, 2020. APF and Summit. [Daring]. Tersedia dalam [https:// gaatw.org/component/content/article?id=478:the-asean-peoples-forum-ap-and summit] (Diakses [21 April 2020]). 
, 2020. GAATW Members in Asia. [Daring]. Tersedia dalam [https://gaatw.org/members/asia] (Diakses [17 Mei 2020]).

2020. Reclaiming Migrant Women's Narratives: A Feminist Participatory Action Research project on 'Safe and Fair' Migration in Asia. [Daring]. Tersedia dalam [https://gaatw.org/publications/Reclaiming\%20Migrant\%20Women's\%20Narratives.pdf] (Diakses [21 April 2020]).

German Asia-Pasific Business Association, 2020. Labour Mobility and the ASEAN Economic Community. [Daring]. Tersedia dalam [https:// www.oav.de/iap-32014/artikel616.html] (Diakses [21 April 2020]).

ILO, 2020. Woman and Men Migrant Workers: Moving Towards Equal Rights and Opportunities. [Daring]. Tersedia dalam [https://www.ilo. org/wcmsp5/groups/public/---dgreports/---gender/documents/publication/wcms_101118.pdf] (Diakses [21 April 2020]).

LRCKJHAM, 2020. Strengthening Sisterhood in Fighting For Women Migrant Workers' Safe and Fair Migration in Curut Village of Central Java, Indonesia. [Daring]. Tersedia dalam [https://gaatw.org/publications/Safe_and_Fair_FPAR/FPAR_Report_LRC-KJHAM.pdf] (Diakses [17 Mei 2020]).

MAP Foundation, 2020. Safe and Fair Migration: A Feminist Perspective of Myanmar Women Migrant Workers in Mae Sot Garment Factories on Women's Rights to Mobility and Decent Work. [Daring]. Tersedia dalam [https://gaatw.org/publications/Safe and_Fair FPAR/FPAR Report MAP.pdf] (Diakses [19 Juni 2020]).

TWC2, 2020. Advocacy. [Daring]. Tersedia dalam [http://twc2.org.sg/ what-we-do/advocacy/] (Diakses [19 Juni 2020]).

, 2020. CEDAW Shadow Report: Singapore 4th Periodic Review, Discrimination Against Women Migrant Workers and Human Trafficking in Singapore. [Daring]. Tersedia dalam [http://twc2.org. sg/wp-content/uploads/2013/o9/CEDAW-Shadow-Report-2011final1.pdf] (Diakses [19 Juni 2020]).

Yazid, S., 2020. Activism of Indonesian NGOs On The Issue of Women Migrant Workers: Engaging in National and International Co-operation", Monash University. [Daring]. Tersedia dalam [http:// repository.unpar.ac.id/bitstream/handle/123456789/1863/MAKLH_Sylvia_Activism of Indonesian-p.pdf? sequence $=3 \&$ isAllowed=y] (Diakses [17 Mei 2020]). 
Monica Vira Ajeng Kristanti

\section{Lain-lain}

Kristanti, M. V. A., 2018. Hasil observasi pada Divisi PWNI. KBRI Singapura. 